\title{
ANALISIS PENENTUAN HARGA JUAL DENGAN METODE COST PLUS PRICING DAN PENGARUHNYA TERHADAP LABA YANG DIHASILKAN PADA UD MAJU
}

\author{
Yunita Sari \\ Program Studi Akuntansi, Politeknik LP3I Medan \\ Lily Karlina Nasution \\ Program Studi Akuntansi, Politeknik LP3I Medan
}

*Corresponding author: E-mail: ysari2406@gmail.com, lilykarlinanasution@gmail.com

\section{Abstrak}

Metode cost plus pricingdenganpendekatanfull costingadalahsalahsatumetode yang banyakdigunakanolehperusahaandalampenentuanhargajualkarenadinilaisebagaimetode yang mudahuntukdipahami. Metode cost plus pricingdenganpendekatanfull costing juga memperhitungkansemuabiaya yang dikeluarkanuntukmemproduksisuatuprodukbaikbiayavariabelmaupunbiayatetap.

Tujuandaripenelitianiniuntukmembantu

Majudalampenentuanhargajualdanuntukmengetahuibesarnyalaba yang diperoleh UD MajuselamabulanJanuari 2018. Penelitianinidilakukanpadasalahsatu Usaha Kecil Menengahyaitu UD Maju yang beralamat di JalanTitiPapan Gang Pemuda, SeiSikambing D, Medan yang dikelolaolehBapakSuparman. Jenis data yang digunakanadalah data primer yaitu data yang diperolehmelaluiobservasidanwawancara. Metodeanalisis data yang digunakanadalahdeskriptifkuantitatifyaitumengelola data berupaangka-angka. Berdasarkanhasilpenelitiandiketahuibahwa

Majubelummelakukanperhitunganhargapokokproduksidanhargajual. Hargajual yang selamainiditetapkanoleh UD Majulebihkecildarihargajual yang dihitungmenggunakanmetodecost plus pricingdenganpendekatanfull costing. Dari hasilpenelitian, dapatdisimpulkanbahwaselamaini UD Majumengalamikerugian.

Kata Kunci :Cost Plus Pricing, Full Costing, HargaJual, Laba.

\begin{abstract}
Cost plus pricing method with full costing approach is one of the many methods used by the company in determining the selling price because it is considered as an easy method to understand. Cost plus pricing method with full costing approach also take into account all expenses incurred to produce a product either variable cost or fixed cost. The purpose of this research is to help UD Maju in determining the selling price and to know the amount of profit obtained by UD Maju during January 2018. This research was conducted on one of Small Medium Enterprises which is UD Maju which is located at JalanTitiPapan Gang Pemuda, SeiSikambingD , Medan managed by Mr. Suparman. The type of data used is primary data that is data obtained through observation and interview. Data analysis method used is descriptive quantitative that is managing data in the form of numbers. Based on the results of the research note that UD Maju has not done the calculation of cost of production and selling price. The selling price set by UD Maju is smaller than the selling price calculated using cost plus pricing method with full costing approach. From the results of the study, it can be concluded that during this UD Maju suffered losses
\end{abstract}


Keywords: Cost Plus Pricing, Full Costing, Selling Price, Profit.

\section{PENDAHULUAN}

Banyak diantara perusahaan industri kecil seperti Usaha Kecil Menengah (UKM) yang tidak memahami secara benar mengenai penentuan harga pokok produksi. Harga pokok produksi berpengaruh terhadap penentuan harga jual. Harga jual yang ditentukan harus dapat menutupi biaya produksi yang dikeluarkan perusahaan agar perusahaan dapat memperoleh laba sesuai dengan yang diharapkan. Untuk itu, perusahaan harus menentukan harga jual dengan tepat agar perusahaan dapat memperoleh laba sesuai dengan yang diharapkan dan jauh dari ancaman kerugian bahkan kebangkrutan. Perusahaan harus menggunakan suatu metode untuk menentukan harga jual salah satunya yaitu metode cost plus pricing.

Menurut penelitian yang terdahulu dilakukan oleh Priandeza (2013) dengan judul "Analisis Penentuan Harga Jual dengan metode Cost Plus Pricing dan Pengaruhnya terhadap Laba pada Toko Karoma Cake" dengan kesimpulan bahwa dalam menentukan harga jual, perusahaan hanya melakukan perhitungan harga jual berdasarkan biaya-biaya yang telah dikeluarkan (biaya bahan baku, biaya tenaga kerja langsung, biaya kotak kardus, biaya plastik, biaya bahan bakar gas, dan biaya administrasi \& umum) serta menentukan harga jual agar perusahaan dapat menutup biaya per unit dengan menambahkan persentase (laba yang diharapkan) per unit. Perbedaan antara penelitian ini dengan penelitian sebelumnya hanya terletak pada objek penelitian.
UD Maju adalah industri yang bergerak dibidang kerajinan rotan. Industri ini memproduksi berbagai jenis kerajinan rotan seperti kursi tamu, ayunan, meja, keranjang parsel dan lain sebagainya. UD Maju menentukan harga jual berdasarkan harga pasar yang ada di kalangan sesama pengrajin rotan. UD Maju tidak mengetahui apakah harga jual yang selama ini ditetapkan dapat menutupi biaya produksi yang dikeluarkan dan dapat memperoleh laba yang diharapkan. Maka dari itu, penulis tertarik untuk mengambil judul "Analisis Penentuan Harga Jual dengan metode Cost Plus Pricing dan Pengaruhnya terhadap Laba yang dihasilkan pada UD Maju."

Berdasarkan latar belakang masalah dalam penelitian ini, maka yang menjadi perumusan masalah dalam penelitian ini adalah bagaimana penentuan harga jual dengan menggunakan metode Cost PlusPricing dengan Pendekatan Full Costing dan berapa laba yang diperoleh perusahaan dengan menggunakan metode Cost PlusPricing dengan Pendekatan Full Costing?

Penelitian hanya dilakukan pada salah satu kerajinan kursi tamu yaitu kursi betawi menurut perusahaan dengan penentuan harga jual dengan metode Cost Plus Pricing dengan pendekatan Full Costing dan pengaruhnya terhadap laba yang dihasilkan pada bulan Januari 2018. Adapun tujuan dalam penelitian ini adalah untuk mengetahui harga jual dan laba yang diperoleh UD Maju dengan metode Cost Plus Pricing dengan pendekatan Full Costing. 


\section{Pengertian Akuntansi Biaya}

Menurut Fitrah dan Endang (dalam

Purnama 2017:14), “Akuntansi biaya merupakan suatu alat bagi manajemen dalam menjalankan aktivitas perusahaan yaitu sebagai alat perencanaan, pengawasan dan pembuatan keputusan."

$$
\text { Menurut Mulyadi (dalam }
$$

Wuryansari 2016:6), "Akuntansi biaya adalah proses pencatatan, penggolongan, peringkasan dan penyajian biaya, pembuatan dan penjualan produk dan jasa, dengan cara-cara tertentu, serta penafsiran terhadapnya."

Dari pendapat ahli diatas, dapat disimpulkan bahwa akuntansi biaya adalah proses pencatatan, penggolongan, peringkasan dan penyajian biaya yang merupakan alat manajemen dalam menjalankan aktivitas perusahaan yaitu sebagai alat perencanaan, pengawasan dan pembuatan keputusan.

\section{Biaya dan Penggolongannya}

Menurut Dunia dan Wasilah (dalam Purnama 2017:16), mendefinisikan "Biaya sebagai pengeluaran-pengeluaran atau nilai pengorbanan untuk memperoleh barang atau jasa yang berguna untuk masa yang akan datang atau mempunyai manfaat melebihi satu periode akuntansi tahunan."

Menurut Siregar dkk (2015:23), "Biaya adalah kos barang atau jasa yang telah memberikan manfaat yang digunakan untuk memperoleh pendapatan."

Berdasarkan pendapat ahli diatas, biaya adalah pengeluaran-pengeluaran untuk mendapatkan barang atau jasa yang berguna untuk saat ini dan masa yang akan datang yang telah memberikan manfaat yang digunakan untuk memperoleh pendapatan.

Menurut Siregar dkk (2015:25-32), pada dasarnya biaya dapat diklasifikasi berdasarkan pada hal-hal berikut ini :

1. Hubungan biaya dengan produk

Berdasarkan hubungannya dengan produk, biaya dapat digolongkan sebagai biaya langsung dan tidak langsung. Biaya langsung adalah biaya yang dapat ditelusur ke produk. Contoh biaya langsung adalah biaya bahan baku. Biaya tidak langsung adalah biaya yang secara langsung tidak dapat ditelusur ke produk. Contoh biaya tidak langsung adalah beban sewa gedung pabrik.

2. Hubungan biaya dengan volume kegiatan

Berdasarkan hubungannya dengan perubahan volume kegiatan, biaya diklasifikasi menjadi tiga yaitu :

a. Biaya variabel (variable cost) adalah biaya yang jumlah totalnya berubah proporsional dengan perubahan volume kegiatan atau produksi tetapi jumlah per unitnya tidak berubah.

b. Biaya tetap (fixed cost) adalah biaya yang jumlah totalnya tidak terpengaruh oleh volume kegiatan dalam kisaran volume tertentu.

c. Biaya campuran (mixed cost) adalah biaya yang jumlahnya terpengaruh oleh volume kegiatan perusahaan tetapi tidak secara proporsional.

3. Elemen biaya produksi

Biaya produksi adalah biaya yang terjadi untuk mengubah bahan baku menjadi barang jadi. Apabila biaya diklasifikaikan berdasarkan elemen biaya produksi maka biaya dibagi menjadi tiga yaitu :

a. Biaya bahan baku (raw materials cost) adalah besarnya nilai bahan 
baku yang dimasukkan ke dalam proses produksi untuk diubah menjadi barang jadi.

b. Biaya tenaga kerja (direct labor cost) adalah besarnya biaya yang terjadi untuk menggunakan tenaga karyawan dalam mengerjakan proses produksi. Biaya tenaga kerja dapat dibedakan menjadi dua kelompok, yaitu biaya tenaga kerja langsung dan biaya tenaga kerja tidak langsung.

c. Biaya overhead pabrik (manufacture overhead cost) adalah biaya-biaya yang terjadi di pabrik selain biaya bahan baku maupun biaya tenaga kerja langsung.

\section{Fungsi pokok perusahaan}

Fungsi pokok perusahaan manufaktur terdiri dari fungsi produksi, fungsi pemasaran serta fungsi administrasi dan umum. Berdasarkan fungsi pokok perusahaan tersebut, biaya dapat diklasifikasikan menjadi tiga antara lain :

a. Biaya produksi (production cost) terdiri atas tiga jenis biaya, yaitu biaya bahan baku, biaya tenaga kerja dan biaya overhead pabrik.

b. Biaya pemasaran (marketing expense) meliputi berbagai biaya yang terjadi untuk memasarkan produk atau jasa.

c. Biaya administrasi dan umum (general and administrative expense) adalah biaya yang terjadi dalam rangka mengarahkan, menjalankan dan mengendalikan perusahaan untuk memproduksi barang jadi.

5. Hubungan biaya dengan proses pokok manajerial

Proses pokok manajerial di perusahaan meliputi perencanaan, pengendalian dan penilaian kinerja.Terdapat beberapa istilah biaya yang sering digunakan dalam rangka melaksanakan fungsi pokok manajerial tersebut antara lain :

a. Biaya standar (standard cost) adalah biaya ditentukan di muka yang seharusnya dikeluarkan untuk membuat suatu produk atau melaksanakan suatu kegiatan.

b. Biaya aktual (actual cost) adalah biaya yang sesungguhnya terjadi untuk membuat suatu produk atau melaksanakan suatu kegiatan.

c. Biaya terkendali (controllable cost) adalah biaya yang secara langsung dapat dipengaruhi oleh seorang manajer tingkatan tertentu.

d. Biaya tidak terkendali (uncontrollable cost) adalah biaya yang tidak secara langsung dapat dipengaruhi oleh seorang manajer tingkatan tertentu.

e. Biaya komitan (committed cost) adalah biaya yang terjadi dalam upaya mempertahankan kapasitas atau kemampuan organisasi dalam kegiatan produksi, pemasaran dan administrasi.

f. Biaya diskresioner (discretionary cost) adalah biaya yang besar kecilnya tergantung pada kebijakan manajemen.

\section{Pengertian Harga Pokok Produksi}

Menurut Mulyadi (dalam Farhah 2017:12), "Harga pokok produksi adalah total biaya-biaya yang terjadi untuk mengolah bahan baku menjadi produk yang siap untuk dijual."

Menurut Supriyono (dalam Wuryansari 2016:11), "Harga pokok produksi adalah semua elemen biaya yang diproduksi baik tetap maupun variabel." 
Dari pendapat para ahli tersebut, dapat disimpulkan harga pokok produksi adalah total dari biaya-biaya baik biaya tetap maupun biaya variabel yang terjadi dalam mengolah bahan baku menjadi produk jadi.

\section{Metode Penentuan Harga Pokok Produksi}

Penentuan harga pokok produksi yang akurat sangat penting untuk analisis profitabilitas dan keputusan strategis yang berkenaan dengan desain produk, penetapan harga dan bauran produk. Menurut Mulyadi (dalam Purnama 2017:27), dalam menentukan harga pokok produksi terdapat berbagai cara atau metode yang dapat digunakan seperti full costing dan variable costing.

\section{Full costing}

Menurut Mulyadi (dalam Purnama 2017:27) full costing merupakan penentuan kos produksi yang memperhitungkan semua unsur biaya produksi ke dalam kos produksi yang terdiri dari biaya bahan baku, biaya tenaga kerja langsung dan biaya overhead pabrik baik yang berperilaku variabel maupun yang berperilaku tetap.

\section{Variable costing}

Menurut Gersil dan Cevdet (dalam Purnama 2017:29), Variable costing adalah metode yang menentukan harga pokok produksi yang hanya memperhitungkan unsur biaya produksi yang berperilaku variabel ke dalam harga pokok produksi, yang terdiri dari biaya bahan baku, biaya tenaga kerja langsung dan biaya overhead pabrik variabel. Sedangkan untuk biaya tetap akan dibebankan pada periode tertentu. Jadi dapat disimpulkan bahwa dengan menggunakan variablecosting barang yang akan dijual tidak mengandung biaya overhead tetap. Variabelcosting lebih banyak digunakan untuk pengambilan keputusan jangka pendek.

\section{Cost Plus Pricing}

Menurut Sodikin (2015:164), harga jual produk harus dapat menutup seluruh biaya perusahaan, bukan hanya biaya produksi, tetapi juga biaya nonproduksi seperti biaya administrasi umum dan pemasaran. Pendekatan yang lazim untuk menentukan harga jual produk standar adalah menerapkan formula cost plus. Menurut pendekatan ini, harga jual adalah biaya (cost) ditambah dengan markup sebesar persentase tertentu dari biaya tersebut. Markup harus ditentukan sedemikian rupa sehingga laba yang diinginkan dapat tercapai.

Dalam pendekatan ini dikenal empat pendekatan dalam menentukan harga jual yaitu :

a. Biaya Produksi Penuh (Full Costing)

Menurut pendekatan ini, biaya produksi terdiri atas biaya bahan baku, biaya tenaga kerja langsung dan overhead pabrik tetap dan variabel.

b. Biaya Penuh (Full Cost)

Full cost adalah seluruh biaya perusahaan yang terdiri atas biaya produksi total (variabel plus tetap) dan biaya nonproduksi total (variabel plus tetap).

c. Biaya Produksi Variabel (Variable Costing)

Menurut pendekatan ini, biaya produk hanya terdiri atas biaya variabel yang diperlukan untuk memproduksi barang/jasa. Elemen biaya produk hanya meliputi biaya bahan baku, biaya tenaga kerja langsung dan biaya overhead pabrik variabel. Biaya overhead pabrik tetap dianggap bukan biaya produksi, melainkan biaya perioda (period cost).

d. Biaya Variabel (Variable Cost) 
Variable cost adalah seluruh biaya variabel baik biaya produksi variabel maupun biaya nonproduksi variabel.

\section{Laba}

Menurut Soemarso S.R (dalam 2017:3), "Laba adalah selisih lebih pendapatan atas biaya-biaya yang terjadi sehubungan dengan kegiatan usaha, untuk memperoleh pendapatan tersebut selama periode tertentu."Menurut Kotler (dalam 2017:3), "Laba adalah pendapatan (revenue) dikurangi biaya-biaya (cost)." Dari pendapat ahli diatas, dapat disimpulkan bahwa laba dalah selisih antara pendapatan dengan biaya-biaya yang terjadi sehubungan dengan kegiatan usaha dalam suatu periode tertentu.

\section{A. METODE PENELITIAN}

Penelitian ini dilakukan oleh penulis di UD Maju yang beralamat di Jalan Titi Papan Gang Pemuda, Sei Sikambing D, Medan. Waktu Penelitian dimulai dari bulan Januari 2018 sampai dengan Februari 2018.Dalam penelitian ini penulis menggunakan data primer yang berupa wawancara langsung dengan pemilik UD Maju guna memperoleh informasi mengenai keuangan dan kegiata-kegiatan yang terjadi di UD Maju.Data yang penulis peroleh berasal dari internal perusahaan yang dalam hal ini berasal dari pemilik UD Maju berupa data mengenai biaya-biaya yang dikeluarkan selama proses produksi, data karyawan dan lain-lain.
Dalam penelitian ini, teknik pengumpulan data yang dilakukan adalah dengan observasi, wawancara serta studi pustaka/ kajian pustaka. Metode yang digunakan dalam menganalisis data penelitian ini adalah dengan menggunakan metode deskriptif kuantitatif. Data diperoleh dari penelitian ini dihitung dengan menggunakan metode full costing untuk menghitung harga pokok produksi dan pendekatan full costing untuk menentukan harga jual kepada konsumen dan untuk menghitung laba yang dihasilkan oleh UD Maju. Tahapan yang dilakukan antara lain sebagai berikut

1. Mengidentifikasi biaya-biaya yang terjadi di perusahaan sesuai dengan teori akuntansi yang ada.

2. Melakukan perhitungan harga pokok produksi menggunakan metode full costing.

3. Menetapkan harga jual.

4. Menghitung laba yang dihasilkan.

\section{B. HASIL DAN PEMBAHASAN}

\section{Perhitungan Harga Pokok Produksi}

UD Maju memproduksi beragam jenis kerajinan rotan salah satunya kursi tamu. Pada saat penulis melakukan penelitian, UD Maju banyak memproduksi salah satu jenis dari kursi tamu yaitu kursi betawi dengan total produksi sebanyak 60 set kursi betawi. Harga jual untuk 1 set kursi betawi sebesar Rp. 850.000,--

Pada bulan Januari 2018, laba yang diperoleh UD Maju dalam memproduksi kursi betawi adalah sebagai berikut :

Tabel 1LaporanLabaRugi

\begin{tabular}{|c|c|}
\hline \multicolumn{4}{|c|}{ Laporan Laba Rugi } \\
\hline \multicolumn{4}{|c|}{ Untuk Periode Yang Berakhir 31 Januari 2018 } \\
\hline Penjualan $=60$ set $\quad$ x $\quad$ Rp. Rp. 51.000.000,-
\end{tabular}




\begin{tabular}{|lll|} 
850.000,-,- & & \\
Biaya Produksi : & & \\
Biaya Bahan Baku & Rp.14.400.000,- \\
Biaya Tenaga Kerja Langsung & Rp. 25.200.000,- \\
Biaya Overhead Pabrik Variabel & Rp. 5.710.000,- & \\
Biaya Overhead Pabrik Tetap & Rp. 24.376,- & \\
Harga Pokok Produksi & & Rp. 45.334.376,-) \\
Laba Kotor & & Rp. 5.665.624,- \\
Biaya Pemasaran & & Rp. 100.000,-) \\
Laba Bersih & & Rp. 5.565.624,-- \\
\hline
\end{tabular}

Sumber: Analisis Penulis (2018)

Adapun biaya-biaya yang dikeluarkan untuk memproduksi 1 set kursi betawi dengan pendekatan full costing adalah sebagai berikut :

Bahan baku yang digunakan untuk menghasilkan 1 set kursi betawi pada bulan Januari 2018 adalah sebagai berikut:

\section{Biaya Bahan Baku}

Tabel 2 Biaya Bahan Baku

\begin{tabular}{|l|l|l|l|l|}
\hline No & Keterangan & $\begin{array}{l}\text { Kuantitas } \\
\text { (batang) }\end{array}$ & Harga/unit & Jumlah \\
\hline 1 & Rotan Getah & 8 & Rp. 7.500,- & Rp. 60.000,- \\
\hline 2 & Rotan Baliong & 15 & Rp. 12.000,- & $\begin{array}{l}\text { Rp. } \\
180.000,-\end{array}$ \\
\hline \multicolumn{2}{|l|}{ BiayaBahan Baku per set } & & & $\begin{array}{l}\text { Rp. } \\
240.000,-\end{array}$ \\
\hline
\end{tabular}

Sumber: Analisis Penulis (2018)

\section{Biaya Tenaga Kerja Langsung}

Tabel 3 Biaya Tenaga Kerja Langsung

\begin{tabular}{|l|l|l|l|l|}
\hline No & Keterangan & $\begin{array}{l}\text { JumlahKa } \\
\text { ryawan }\end{array}$ & Upah/set & Jumlah \\
\hline 1 & $\begin{array}{l}\text { BagianPembuatanKerangk } \\
\text { a }\end{array}$ & 1 & Rp. 60.000,- & Rp. 60.000,- \\
\hline 2 & BagianPenganyaman & 1 & Rp. 160.000,- & Rp. 160.000,- \\
\hline 2 & BagianPengecatan & 1 & Rp. 200.000,- & Rp. 200.000,- \\
\hline BTKL Per Set & & & Rp. 420.000,- \\
\hline
\end{tabular}

Sumber: Analisis Penulis (2018)

\section{Biaya Overhead Pabrik}

Biaya overhead pabrik terdiri dari biaya overhead pabrik tetap dan biaya overhead pabrik variabel. Persentase biaya overhead pabrik tetap dan biaya overhead pabrik variabel yang dibebankan ke produk kursi betawi sebesar 25\%. Rincian biaya overhead pabrik adalah sebagai berikut: 
Tabel 4 Biaya Overhead Pabrik

\begin{tabular}{|c|c|c|c|c|}
\hline No. & Keterangan & Variabel & Tetap & Jumlah \\
\hline 1 & $\begin{array}{l}\text { BahanPenolong: } \\
\text { Plitur } \\
\text { Tiner } \\
\text { Staples } \\
\text { Sekrup } \\
\text { Paku Kecil }\end{array}$ & $\begin{array}{l}\text { Rp. } 1.500 .000,- \\
\text { Rp. } 900.000,- \\
\text { Rp. } 1.050 .000,- \\
\text { Rp. } 1.200 .000,- \\
\text { Rp. } 960.000,-\end{array}$ & & Rp. 5.610.000,- \\
\hline 2 & $\begin{array}{l}\text { PenyusutanPeralatan } \\
: \\
\text { Stapler } \\
\text { Gergaji } \\
\text { MesinKompressor } \\
\text { AlatPembengkok } \\
\text { Rotan } \\
\text { AlatPemotong Rotan } \\
\text { Palu } \\
\text { Tang }\end{array}$ & & $\begin{array}{l}\text { Rp. } 1.458,- \\
\text { Rp. } 1.563,- \\
\text { Rp. } 10.417,- \\
\text { Rp. } 1.563,- \\
\text { Rp. } 6.250,- \\
\text { Rp. } 2.083,- \\
\text { Rp. } 1.042,-\end{array}$ & Rp. $\quad 24.376,-$ \\
\hline 3 & BiayaListrik & Rp. $\quad 60.000,-$ & & $60.000,-$ \\
\hline 4 & BiayaTelepon/Pulsa & Rp. $\quad 40.000,-$ & & Rp. $\quad 40.000,-$ \\
\hline & BiayaOverheadPabrik & $\begin{array}{l}\text { Rp. } \\
5.710 .000,-\end{array}$ & Rp.24.376,- & Rp. 5.734.376,- \\
\hline
\end{tabular}

Sumber: Analisis Penulis (2018)

Metode full costing adalah metode kerja langsung, dan biaya overhead pabrik. perhitungan harga pokok produksi dengan Berikut perhitungan biaya produksi memperhitungkan semua biaya produksi dengan metode full costing: seperti biaya bahan baku, biaya tenaga

Tabel 5 Biaya Produksi

\begin{tabular}{|c|l|c|c|c|}
\hline No & \multicolumn{1}{|c|}{ Keterangan } & $\begin{array}{c}\text { Unit yang } \\
\text { diproduks } \\
\text { i }\end{array}$ & Biaya/unit & Total \\
\hline 1 & Biaya Bahan Baku & 60 & Rp. 240.000,- & Rp. 14.400.000,- \\
\hline 2 & $\begin{array}{l}\text { Biaya Tenaga Kerja } \\
\text { Langsung }\end{array}$ & 60 & Rp. 420.000,- & Rp. 25.200.000,- \\
\hline 3 & $\begin{array}{l}\text { BiayaOverhead } \\
\text { Pabrik }\end{array}$ & & & Rp. 5.734.376,- \\
\hline & Total Biaya Produksi & & & Rp. 45.334.376,- \\
\hline
\end{tabular}

Sumber: Analisis Penulis (2018) 
Penentuan Harga Jual dengan metode metode cost plus pricing dengan Cost Plus Pricing dengan pendekatan pendekatan full costing yaitu biaya Full Costing

Unsur-unsur biaya yang digunakan produksi dan biaya non produksi. Biaya non produksi terdiri dari :

untuk menetapkan harga jual dengan

Tabel 6 Biaya Non Produksi

\begin{tabular}{|l|l|l|}
\hline No. & Keterangan & Jumlah \\
\hline 1 & BiayaPemasaran & Rp. 100.000,- \\
\hline & Jumlah & Rp. 100.000,- \\
\hline
\end{tabular}

\section{Sumber: Analisis Penulis (2018)}

Perhitungan unsur biaya penuh pricingdengan pendekatan full costing menggunakan metode cost plus dapat dilihat pada tabel berikut:

Tabel 7 Perhitungan Biaya Penuh dengan Pendekatan Full Costing

\begin{tabular}{|lc|}
\hline Biaya Bahan Baku & Rp. $14.400 .000,-$ \\
Biaya Tenaga Kerja Langsung & Rp. 25.200.000,- \\
Biaya Overhead Pabrik Tetap & Rp. 24.376,- \\
Biaya Overhead Pabrik Variabel & Rp. 5.710.000,-, + \\
Biaya Penuh & Rp. 45.334.376,-- \\
Unit yang diproduksi & 60 set : \\
Biaya Penuh per Unit & Rp. 755.573,- \\
\hline
\end{tabular}

Sumber: Analisis Penulis (2018)

Perhitungan markup dimana laba dengan investasi sebesar Rp. 50.000.000,yang diharapkan perusahaan sebesar $30 \%$ yaitu:

Tabel 8 Perhitungan Markup

$\begin{aligned} & \% \text { markup }=\frac{(\text { Target ROI })+(\text { Biaya Pemasaran dan Administrasi Total })}{(\text { Volume dalam Unit }) \times(\text { Biaya Penuh per Unit })} \\ & \% \text { markup }=\frac{(30 \% \text { x Rp. } 50.000 .000,-)+(\text { Rp. } 100.000,-)}{(60) \times(\text { Rp. } 755.573,-)} \\ & \% \text { markup }= \text { (Rp. 15.000.000,-) }+(\text { Rp. 100.000,-) } \\ & \text { Rp. 45.334.380,- } \\ & \% \text { markup }=\frac{\text { Rp. } 15.100 .000,-}{\text { Rp. } 45.334 .380,-} \\ & \text { markup }=33 \%\end{aligned}$

Sumber: Analisis Penulis (2018) 
Setelah diperoleh persentase markup betawi per unit dilampirkan pada tabel sebesar $33 \%$, maka harga jual kursi berikut:

Tabel 9 Perhitungan Harga Jual Kursi Betawi per Unit

\begin{tabular}{|lc|}
\hline Biaya produksi & Rp. 45.334.376,- \\
Markup (33\% x Rp.45.334.376,-) & Rp. 14.960.344,-- \\
Jumlah harga jual & Rp. 60.294.720,- \\
Volume produk & $\frac{60 \text { set : }}{\text { Harga jual per unit }}$ \\
\hline
\end{tabular}

Sumber: Analisis Penulis (2018)

\section{LaporanLabaRugiuntukProdukKursiBetawi}

Tabel 10 LaporanLabaRugi

\begin{tabular}{|c|c|c|}
\hline \multicolumn{3}{|c|}{ UD Maju } \\
\hline \multicolumn{3}{|c|}{ Laporan Laba Rugi } \\
\hline \multicolumn{3}{|c|}{ Untuk Periode Yang Berakhir 31 Januari 2018} \\
\hline Penjualan $=60$ set $\mathrm{x}$ Rp. & & Rp. 60.294.720,- \\
\hline $1.004 .912,-$ & & \\
\hline Biaya Produksi : & & \\
\hline Biaya Bahan Baku & Rp.14.400.000,- & \\
\hline Biaya Tenaga Kerja Langsung & Rp. 25.200.000,- & \\
\hline Biaya Overhead Pabrik Variabel & Rp. 5.710.000,- & \\
\hline Biaya Overhead Pabrik Tetap & Rp. $\quad 24.376,-$ & \\
\hline Harga Pokok Produksi & & (Rp. 45.334.376,- \\
\hline & & 2 \\
\hline Laba Kotor & & Rp. 14.960.344,- \\
\hline Biaya Pemasaran & & (Rp. 100.000,-) \\
\hline Laba Bersih & & Rp. 14.860.344,- \\
\hline
\end{tabular}

Sumber: Analisis Penulis (2018)

UD Maju belum melakukan perhitungan harga pokok produksi dan harga jual yang sesuai dengan teori akuntansi yang ada. Selama ini, UD Maju menentukan harga jual berdasarkan harga pasar. UD Maju juga belum menggolongkan biaya-biaya yang terjadi dalam kegiatan produksi. Dengan menggunakan pendekatan full costing, rincian biaya-biaya untuk memproduksi 60 set kursi betawi adalah sebagai berikut

Tabel 11 Rincian biaya 


\begin{tabular}{|l|l|}
\hline Biaya Bahan Baku & Rp. $14.400 .000,-$ \\
\hline Biaya Tenaga Kerja Langsung & Rp. $25.200 .000,-$ \\
\hline Biaya Overhead Pabrik Tetap & Rp. $24.376,-$ \\
\hline Biaya Overhead Pabrik Variabel & Rp. $5.710 .000,-$ \\
\hline Biaya Pemasaran & Rp. $100.000,-$ \\
\hline Markup & \multicolumn{2}{|c|}{$33 \%$} \\
\hline Harga jual per set & Rp. $1.004 .912,-$ \\
\hline
\end{tabular}

Sumber: Analisis Penulis (2018)

Berdasarkan perhitungan yang penulis 2018 yang ditetapkan perusahaan dengan lakukan, perbandingan harga jual untuk pendekatan full costing pada UD Maju produksi kursi betawi pada bulan Januari adalah sebagai berikut:

Tabel 12 Perbandingan Harga Jual

\begin{tabular}{|l|lr|}
\hline Harga jual per set menurut UD Maju & Rp. & 850.000,- \\
\hline $\begin{array}{l}\text { Harga jual per set berdasarkan pendekatan full } \\
\text { costing }\end{array}$ & Rp. $1.004 .912,-$ \\
\hline Selisih harga jual & Rp. & 54.912,-- \\
\hline
\end{tabular}

Sumber: Analisis Penulis (2018)

Selisih harga jual yang ditetapkan UD Maju dengan harga jual menggunakan pendekatan full costing sebesar Rp. 54.912,- per set. Harga jual yang ditetapkan UD Maju lebih rendah dari harga jual yang dihitung dengan pendekatan full costing. Hal ini menunjukkan bahwa UD Maju mengalami kerugian.

Perbandingan laba bersih yang diperoleh UD Maju dengan metode perusahaan dengan menggunakan metode cost plus pricing pendekatan full costing adalah sebagai berikut:

Tabel 13 Perbandingan Laba Bersih

\begin{tabular}{|l|l|}
\hline Laba bersih menurut UD Maju & Rp. 5.565.624,-- \\
\hline Laba bersih berdasarkan pendekatan full costing & Rp. 14.860.344,- \\
\hline Selisih laba bersih & Rp. 9.294.720,-- \\
\hline
\end{tabular}

Sumber: Analisis Penulis (2018)

Pada tabel diatas dijelaskan bahwa selisih laba bersih yang diperoleh UD Maju sebesar Rp. 9.294.720,-. Maka dari itu, UD Maju harus melakukan perhitungan harga pokok produksi dan menentukan harga jual dengan tepat sesuai dengan teori akuntansi yang ada agar UD Maju dapat memperoleh laba semaksimal mungkin dan dapat terhindar dari kerugian 


\section{KESIMPULAN}

Berdasarkan penelitian yang penulis bahas pada bab sebelumnya, dapat disimpulkan bahwa penetapan harga jual yang selama ini dilakukan oleh UD Maju belum tepat. Harga jual yang ditetapkan UD Maju untuk produk kursi betawi sebesar Rp. 850.000,-/set sedangkan berdasarkan perhitungan yang penulis lakukan menggunakan metode cost plus pricing dengan pendekatan full costing sebesar Rp. 884.020,-/set.

Laba bersih yang diperoleh UD Maju dengan metode perusahaan sebesar Rp. 5.565.624,- sedangkan dengan menggunakan metode cost plus pricing dengan pendekatan full costing sebesarRp. 14.860.344,-. Selisih antara laba yang diperoleh UD Maju dengan metode perusahaan dengan pendekatan full costing sebesar Rp. 9.294.720,-.

\section{DAFTAR PUSTAKA}

S, B, dkk, (2015), Akuntansi Biaya Edisi 2, Jakarta : Salemba Empat.

S, S.S, (2015), Akuntansi Managemen Sebuah Pengantar, Yogyakarta : UPP STIM YKPN.

S, V. W, (2015), Metodologi Penelitian Bisnis \& Ekonomi, Yogyakarta : PUSTAKABARUPRESS

A, N, (2013), Analisis Penentuan Harga Jual per Kemasan Produk terhadap Laba yang dihasilkan pada PT. Indofood CBP Sukses Makmur Tbk Palembang. 3.

F, S, (2017), Penerapan Metode ABC untuk Penentuan Harga Pokok Produksi pada CV. Rumah Kerudung Jihan.
Skripsi. Institut Agama Islam Negeri Surakarta.

P, C, (2017), Analisis Penentuan Harga Jual dengan Metode Cost Plus Pricing dan Pengaruhnya terhadap Laba pada Toko Karoma Cake. 2-11.

P, D, (2017), Perhitungan Harga Pokok Produksi dalam Menentukan Harga Jual melalui Metode Cost Plus Pricing dengan Pendekatan Full Costing (Studi Kasus PT.PRIMA ISTIQAMAH SEJAHTERA DI $M A K A S S A R$ ). Skripsi. UIN Alauddin Makassar.

W, A, (2016), Analisis Perhitungan Harga Pokok Produksi dengan Menggunakan Metode Full Costing sebagai Dasar Penentuan Harga Jual (Studi Kasus di Peternakan Seraphine Yogyakarta). Skripsi. Universitas Sanata Dharma. 